\section{Identification of patients in medical publications: need for informed consent}

\section{Magne Nylenna, Povl Riis}

Journal of the Norwegian

Medical Association,

$\mathrm{N}-1324$, Lysaker, Norway

Magne Nylenna, MD, editor

Department of

Gastroenterology,

Herlev University

Hospital, DK-2730 Herlev,

Denmark

Povl Riis, MD, former editor of

"Fournal of the Danish

Medical Association"

Correspondence to:

Dr Nylenna.

BMF 1991;302:1182 clinical reporting. the eyes and removing superfluous social details.
In medical journals patients are sometimes identified through clinical photographs or detailed descriptions of their sex, age, accommodation, occupation, etc. Occasionally, such details are relevant for the scientific message; sometimes they are included only because of a tradition of painstaking presentation of details in

How often a patient's identity is unduly disclosed is not known. Recent studies contain only a few examples..$^{1-5}$ We have encountered several disclosures in our journals, which have caused reaction in patients and relatives, despite longstanding policies of masking

To investigate current editorial opinion on this subject we approached several editors of medical journals and asked them to describe their policies and to comment on the possible need for a set of guidelines.

\section{Methods and results}

We conducted a postal survey in September 1990 among medical editors of 116 medical journals from different geographic areas and specialties in which the publication of case descriptions (that is, individual case reports and multiple case descriptions) was thought to represent a possible confidentiality problem. The editors were asked to give basic information on their journal, their own background and editorial experience, their practice in securing confidentiality in case descriptions, and any complaints or episodes of unintended breach of confidentiality during the past 12 months. Their attitudes were investigated through their agreement or disagreement, on a five point scale, with statements in the table. Statistical analyses were performed with the $\chi^{2}$ test and Student's $t$ test.

Ninety editors $(78 \%)$ answered the questionnaire after one reminder. Twenty three of their journals had their editorial office in Scandinavia, 33 in the rest of Europe, and 28 in the United States. Seventy five published case reports, but only seven required informed consent from patients. Thirteen journals had written rules for securing confidentiality; this was more common in the United States than in Scandinavia and the rest of Europe $(p<0 \cdot 005)$. Thirty five that published case reports had specific rules for photographs of patients. Seventeen accepted slight changes of factual information.

Five editors had experienced episodes or complaints as regards to patient confidentiality during the past 12 months. Fifty four agreed that international guidelines for securing patient confidentiality are needed; Scandinavian editors were more in favour than nonNordic European and American editors $(p<0.05)$; and only 20 editors disagreed. Thirty seven agreed that informed consent ought to be obtained, while 41 disagreed. Editors of journals that did not publish case descriptions were more in favour of requiring informed consent than those who did $(p<0.005)$. American and Scandinavian editors were more in favour than others $(p<0 \cdot 005)$. Eighty two agreed that consent should be obtained when presenting clinical photographs and 66 that factual information should never be changed in case descriptions.

No association was found between attitudes to confidentiality and the journal's circulation; number of issues per year; readership; or the editor's age, experience, and full time or part time appointment.

\section{Comment}

Editors do not live up to their principles. Though half of the editors thought that informed consent should be obligatory, less than a tenth of journals publishing case reports required informed consent from patients and less than a fifth had fixed rules for protecting patients' confidentiality. And while almost all editors agreed that informed consent is needed when publishing photographs of patients, only half of the journals had rules for permission to publish such material. Most editors were opposed to altering patient details to deter recognition, but we were surprised that a quarter of the journals accepted slight changes of factual information as this is not in accordance with editorial credibility.

Securing patients' confidentiality in medical publications is not easy, nor even always possible. Masking patients' eyes sometimes also masks important clinical traits or does not prevent identification. ${ }^{3}$ Deleting details of case history is sometimes possible but often the author's name, the institution, plus some supplementary information, are sufficient to identify the patient. ${ }^{4}$ This strongly suggests that consent from the patient or relatives ought to be a condition for publication of case descriptions, at least where the slightest risk of identification exists. Our study also confirms that there is a need for guidelines on confidentiality for patients. The International Committee of Medical Journal Editors have approved such guidelines ( $\mathrm{p}$ 1194).

\footnotetext{
Riesenberg DE. Case reports in the medical literature. CBE Views 1990;13: $8-10$

Squires BP. Case reports: what editors want from authors and peer reviewers. Can Med Assoc $\mathcal{7}$ 1989;141:379-80.

Slue WE. Unmasking the lone rider. N Engl f Med 1989;321:550-1.

4 Morgan C. Confidentiality in a case report. Lancet 1985; i:644.

5 Miles SH. Paternalism, family duries, and my aunt Maude. FAMA 1988:259. $2582-3$.

Accepted 22 April 1991)
}

\section{Correction}

Assessment of cognitive and psychomotor function and rehabilitation of elderly people with prostheses

An editorial error occurred in this paper by Mr R S Hanspal and Keren Fisher (20 April, p 940). In the table the footnote t should not have appeared; the footnote $\neq$ should have read " $\neq$ Confidence intervals could not be calculated. Two of the three patients could not complete the maze."

\begin{tabular}{|c|c|c|c|c|c|c|}
\hline & $\begin{array}{l}\text { Completely } \\
\text { agreed }\end{array}$ & $\begin{array}{l}\text { Partly } \\
\text { agreed }\end{array}$ & $\begin{array}{c}\text { Were } \\
\text { indifferent }\end{array}$ & $\begin{array}{c}\text { Partly } \\
\text { disagreed }\end{array}$ & $\begin{array}{l}\text { Completely } \\
\text { disagreed }\end{array}$ & $\begin{array}{l}\text { Had no } \\
\text { opinion }\end{array}$ \\
\hline International guidelines for securing patients' confidentiality in medical publishing are needed & 29 & 25 & 9 & 5 & 15 & \\
\hline Informed consent should routinely be obtained (if possible) when publishing case reports & 19 & 18 & 5 & 14 & 27 & 7 \\
\hline $\begin{array}{l}\text { Informed consent should be obtained when presenting photographs or other material making identification of the } \\
\text { patient possible }\end{array}$ & 78 & 4 & & & 3 & 5 \\
\hline Factual information should never be altered in case reports & 2 & 14 & 3 & 5 & 10 & 6 \\
\hline A case report should never be published, however well anonymised, if the patient refuses publication & 40 & 12 & & 15 & 11 & 12 \\
\hline
\end{tabular}

